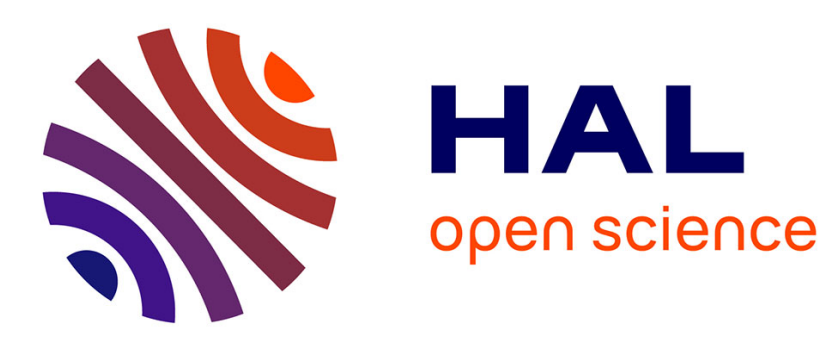

\title{
ACD Modeling of Homogeneous Job Shops Having Inline Cells
}

\author{
Hyeonsik Kim, Byoung K. Choi, Hayong Shin
}

\section{To cite this version:}

Hyeonsik Kim, Byoung K. Choi, Hayong Shin. ACD Modeling of Homogeneous Job Shops Having Inline Cells. IFIP International Conference on Advances in Production Management Systems (APMS), Sep 2015, Tokyo, Japan. pp.340-347, 10.1007/978-3-319-22756-6_42 . hal-01417505

\section{HAL Id: hal-01417505 \\ https://hal.science/hal-01417505}

Submitted on 15 Dec 2016

HAL is a multi-disciplinary open access archive for the deposit and dissemination of scientific research documents, whether they are published or not. The documents may come from teaching and research institutions in France or abroad, or from public or private research centers.
L'archive ouverte pluridisciplinaire HAL, est destinée au dépôt et à la diffusion de documents scientifiques de niveau recherche, publiés ou non, émanant des établissements d'enseignement et de recherche français ou étrangers, des laboratoires publics ou privés. 


\title{
ACD Modeling of Homogeneous Job Shops having Inline Cells
}

\author{
Hyeonsik Kim ${ }^{1}$, Byoung K. Choi ${ }^{1 *}$, and Hayong Shin ${ }^{1}$ \\ ${ }^{1}$ Department of Industrial and Systems Engineering, KAIST, Daejeon, Republic of Korea \\ \{hyeonsik.kim, bkchoi, hyshin\}@kaist.ac.kr
}

\begin{abstract}
In an electronics fabrication line, processing devices are arranged as a network of inline cells. Recently, the use of simulation has evolved into online simulation, which is used in simulation-based operational management, from the traditional offline analysis of facility layout and dispatching rules. An online simulation starts with the current state of the manufacturing facilities at any point of time. This paper presents a systematic procedure for building activity cycle diagram (ACD) models of homogeneous job shops having inline cells. In order to demonstrate the effectiveness of the proposed approach, an ACD model was developed for a simple homogeneous job shop having bi-inline cells and a dedicated simulator was also developed.
\end{abstract}

Keywords: Production simulation, Activity cycle diagram, Homogeneous job shop, Inline cell, Online simulation

\section{Introduction}

In an electronics fabrication line (Fab), such as a flat panel display (FPD) production line [1] or a semiconductor fabrication line [2], processing devices are arranged as a network of inline cells. An inline cell consists of a small number of processing devices and an inner conveyor system that carries individual work-pieces through the processing devices along the conveyor belt [2]. Unlike a table-type machine that processes one work-piece at a time, an inline cell processes a batch of work-pieces simultaneously: each work-piece is loaded at its loading port with an inter-loading time (called takt time) and travels through the inline cell for a duration of flow time to be unloaded at the unloading port. Inline cells in a Fab are usually grouped into a number of stations (called inline stockers in a FPD Fab or bays in a semiconductor Fab) and they are connected by an automated material handling system (AMHS) in which cassettes containing individual work-pieces (e.g., glasses or wafers) are transported in the Fab.

The inline cells are largely classified into two types: bi-inline cells and uni-inline cells. This classification is based on whether the work-pieces are loaded and unloaded in the same port: In a bi-inline cell, work-pieces are loaded at a loading port (called the in-port) and are unloaded at a separate unloading port (called the out-port) of the cell; in a uni-inline cell, work-pieces are loaded and unloaded at the same port (called 
the in/out-port). A new (unfinished) work-piece is loaded from a 'new' cassette in the cell; a finished work-piece is unloaded from the cell into an empty cassette. Fig. 1 shows a portion of a (hypothetical) FPD Fab in which all the inline cells are of biinline type. There are eight bi-inline cells (PH: photo-lithography; ET: etching; CLN: cleaning; DEP: deposition) grouped into two stations (i.e. inline stockers). The two stations are connected by a pair of uni-directional conveyors. This kind of job shop consisting of the same type of equipment is referred to as a homogeneous job shop. A job shop consisting of mixed types of equipment is referred to as a heterogeneous job shop.

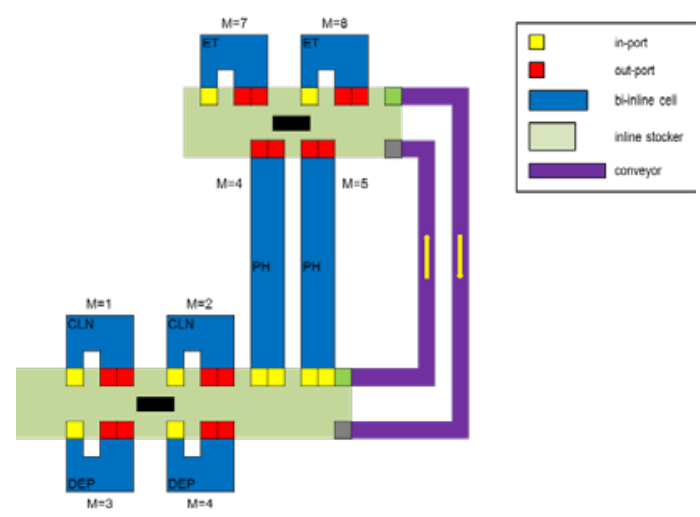

Fig. 1. Layout of a portion of a hypothetical FPD Fab

Recently, the use of a simulation has evolved into the day-to-day operational management of facilities, from the traditional offline analysis of facility layout and dispatching rules $[3,4,5]$. Online simulation is used in simulation-based operational management. An online simulation starts with the current state of the manufacturing facilities at any point of time [6], and it provides the stakeholders with the ability to evaluate the capacity of the facility for new orders and unforeseen events, and to predict the expected delivery times and changes in operations [4].

Many commercial simulation packages have been introduced to simulate a production system. ASAP (AutoSched APTM) is one of the most popular tools for production simulation [7,8,9]. More recently, ManPy, a semantic-free open-source discrete-event simulation package, was also used in developing a job shop simulator [10]. However, a simulator implemented with a simulation package generally has less flexibility than one implemented based on a well-defined formal modeling tool such as an event graph or activity cycle diagram (ACD) [11]. Indeed, the event graph is widely used in modeling and simulation of job shops. Notable examples include event graph modeling of a homogeneous job shop with bi-inline cells [12] and event graph modeling of a heterogeneous job shop with inline cells [13]. However, these event graph models are not suitable for an online simulation because representing the current state of a real system as the initial state of the event graph model is difficult.

This paper presents a systematic procedure for building ACD models of homogeneous job shops having inline cells. Parameterized ACD (PACD) [11, 14] is used to 
build the models of the homogeneous job shops. Compared to the event graph modeling approach [12, 13], the ACD modeling approach presented in this paper has some distinctive advantages: The ACD model is 1) easier to build and validate, 2) more intuitive so that a layman can understand the model more easily, and 3) suitable for online simulation because the current state of a real job shop can easily be reflected in the model. In order to demonstrate the effectiveness of the proposed approach, a PACD model was developed for a simple homogenous job shop having bi-inline cells and a dedicated simulator was developed to make simulation runs with input data.

\section{$2 \quad$ ACD Modeling of Inline Cells}

Fig. 2 is a schematic description of bi-inline cells in FPD Fab. It is used as a reference model from which an ACD model is to be obtained. An arriving cassette enters the cell queue (Q) of the inline cell, and the cassettes in the queue are loaded on the inport (PI) if there is room. The glass loading operation is performed by the track-in robot (TI) to load the glasses into the inline cell. The loaded glasses are processed until they reach the end of the line where the glass unloading operation is performed by the track-out robot (TO), which puts the finished glasses into an empty cassette on an out-port (PO). When the unloading cassette becomes full, it is removed so that an empty cassette can be supplied. A cassette that is emptied at the loading section should also be removed to make room for the next arriving cassette.

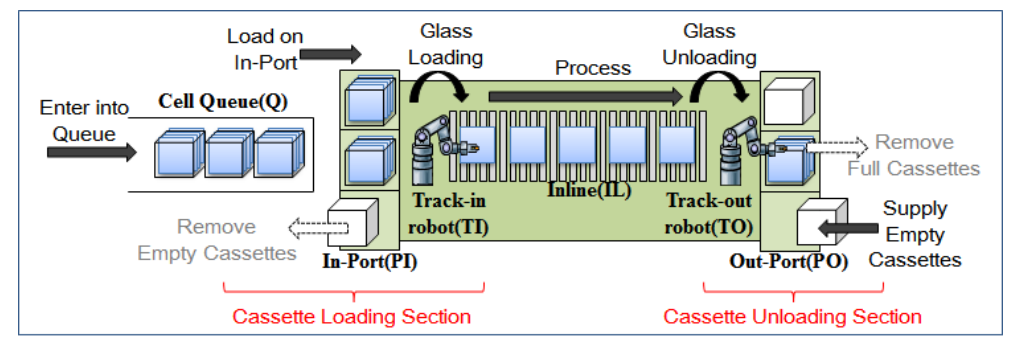

Fig. 2. Reference model of bi-inline cells in FPD Fab

Fig.3 shows an ACD model of the bi-inline cell given in Fig.2. The activities in Fig.2 are modeled as regular activities (solid-line rectangle) in the ACD model:

- Enter (for 'enter into queue' in Fig.2) with activity time te (inter-arrival time);

- LoadPI (load a cassette on In-Port) with tLPI (time for loading a cassette at In-Port);

- LoadG (glass loading) with tL (time for loading all glasses in a cassette);

- ProcessFG (process the $1^{\text {st }}$ glass of a cassette) with $t_{E}$ (inter-arrival time).

- UnloadG (glass unloading) with tтio (track-in/out time for a cassette of glasses);

- SupplyEC (supply empty cassettes) with tsec (time for supplying empty cassette).

The ACD model contains a computation activity (dotted-line rectangle) and an instant activity ('thin' rectangle) as well. A regular activity has a time delay value denoting the activity duration. A computation activity is used for computing variables 
without time delay. The table in Fig. 3 shows detailed computation actions for the computation activity ProcTime (If the job type of the current cassette differs from the last cassette id lastID, a set-up time ts is added). An instant activity denotes an event such as the start of an activity. There are two parameters in the ACD model, j for job type and $p$ for processing step.

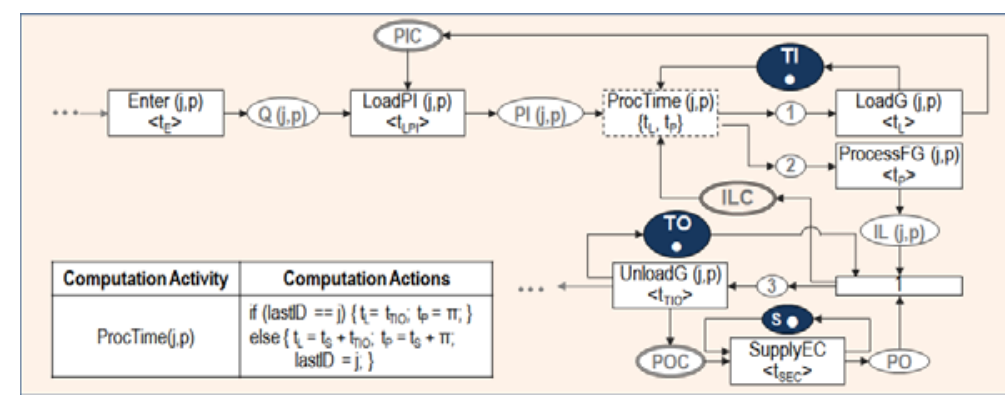

Fig. 3. ACD model of the bi-inline cell in Fig.2

Queues in the ACD model are classified into four types: Entity queue (solid line circle) for the number of entities, resource queue (intaglio circle) for the number of available resources, capacity queue (double-line circle) for the number of available seats, and instant queue (small circle) in which tokens do not stay.

- Entity queues are Q (cassettes in the cell queue), PI (cassettes in the In-Port), IL (cassettes in the inline), and PO (empty cassettes in Out-Port);

- Resource queues are TI (track-in robot), TO (track-out robot), and S (emptycassette supplying system);

- Capacity queues are PIC (capacity or available slots in the In-Port), POC (available slots in the Out-Port), and ILC (available slots in the inline).

Let $\mathrm{N}_{\mathrm{PI}}, \mathrm{N}_{\mathrm{IL}}$, and $\mathrm{N}_{\mathrm{PO}}$ denote the capacities of In-Port, Inline and Out-Port, and then the following relations should hold: $\mathrm{N}_{\mathrm{PI}}=\mathrm{PI}+\mathrm{PIC} ; \mathrm{N}_{\mathrm{LL}}=\mathrm{IL}+\mathrm{ILC} ; \mathrm{N}_{\mathrm{PO}}=\mathrm{PO}+\mathrm{POC}$

Fig. 4 shows an ACD model of a uni-inline cell where the regular queue PU is the number of cassettes in the in/out port region of the uni-inline cell and the capacity queue PUC denotes the number of available ports in the in/out port region. The token in the resource queue TIO is used either by the LoadG activity or by the UnloadG activity (LoadG has a higher priority).

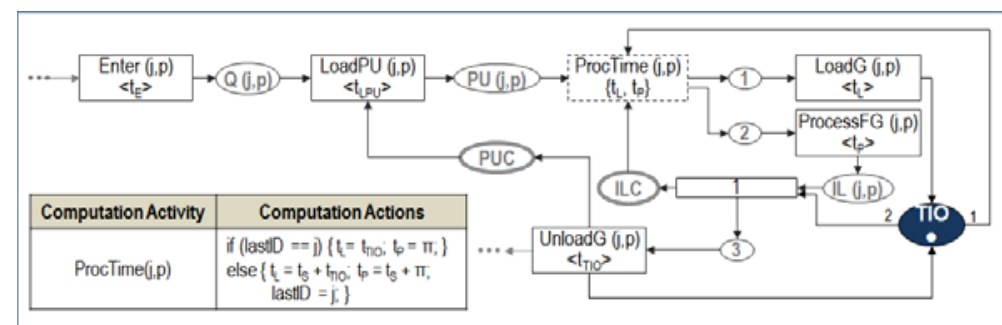

Fig. 4. ACD model of a uni-inline cell 
The behavior of a uni-inline cell is identical to that of a bi-inline cell, except loading and unloading of glasses are done at the same port and track-in and track-out operations are performed by the same robot (track-in/out robot). Also, in a uni-inline cell, there is no need for supplying empty cassettes because the finished glasses are unloaded to the cassette from which the glasses were loaded.

\section{ACD Modeling of Homogeneous Job Shop having Inline Cells}

This section describes how to build an ACD model of a homogeneous job. Fig. 5 shows an ACD model of a job shop consisting of a number of bi-inline cells and a material handling system. The bi-inline cell model of Fig.3 is parameterized with parameter ' $b$ ' and then connected to the ACD model of the material handling system to obtain a parameterized ACD (PACD) model of the homogeneous job shop.

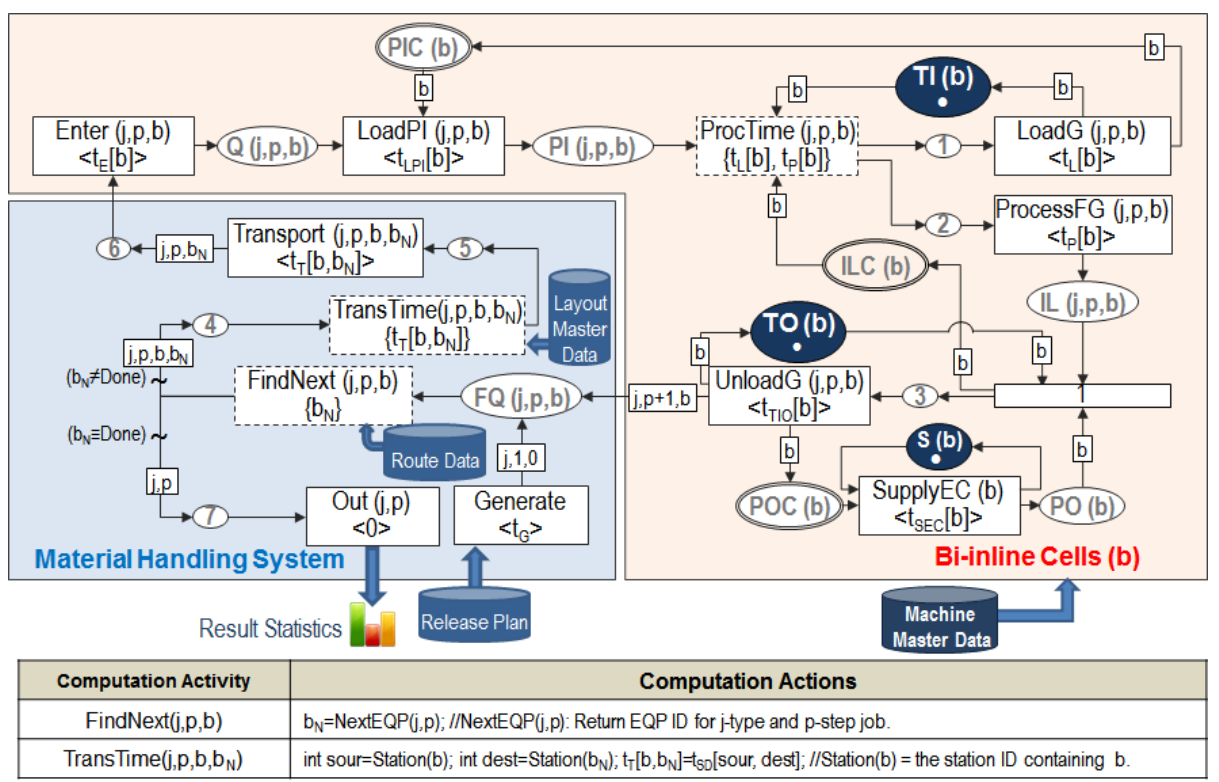

Fig. 5. Parameterized ACD model of a homogeneous job shop having bi-inline cells

In the material handling part of the PACD model, arriving cassettes are generated and stored in the entity queue FQ by the Generate activity based on the Release Plan. A bi-inline cell is selected for the generated cassette at the computation activity FindNext according to the Route Data. The transporting time tr from the current location ' $b$ ' to the target bi-inline cell ' $\mathrm{b}_{\mathrm{N}}$ ' is then computed at the computation activity TransTime referring to the data in the Layout Master Data. Finally, the cassette is transported to the target cell by the regular activity Transport. A cassette containing glasses processed at an inline cell is also stored in FQ, and then it is routed to the next inline cell by the Transport activity or disposed by the Dispose activity if it has completed all the processing steps. 
The upper diagram in Fig. 6 shows an example of the current state of a bi-inline cell. There are seven cassettes with glasses and one empty cassette in the diagram: three cassettes in Q, one in PI, two in IL, and so on. The cassette in PI, for example, contains glasses of type- $1(j=1)$ waiting for the $5^{\text {th }}$ processing $(p=5)$. Currently, both robots are idle ( $\mathrm{TI}=1, \mathrm{TO}=1)$. The current state data of the bi-inline cell ' $\mathrm{b}$ ' can be summarized as shown in the Current State Table in the middle part of Fig.6.

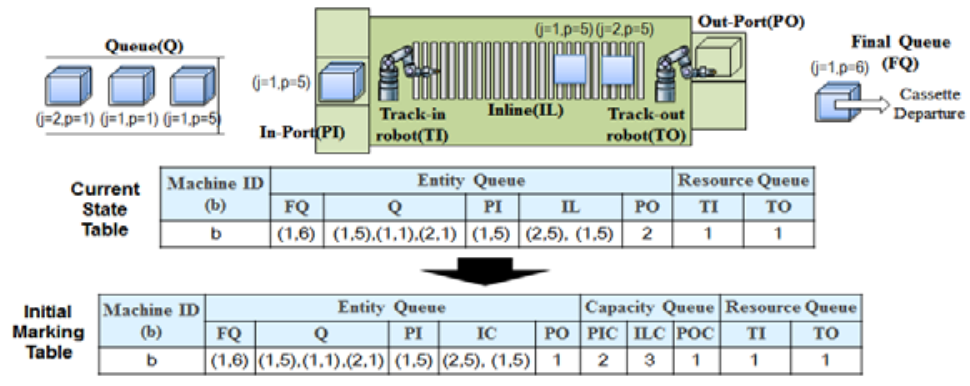

Fig. 6. Procedure for initializing state of bi-inline cell \#b from current state

Finally, the Initial Marking Table shown at the bottom of Fig.6 can be construccted automatically from the Current State Table. Each entry in the capacity queue column is computed by subtracting the number of cassettes from the capacity value in the queue (e.g., PIC $=3-|\mathrm{PI}|=3-1=2$ ). The ability to obtain the initial marking values from the current state data of the Fab makes it easier for the ACD model to be used in an online simulation for real-time operation management.

If the bi-inline cell part of the PACD model in Fig. 5 is replaced by a PACD model of uni-inline cell (See Fig.4), we obtain a homogeneous job shop having uni-inline cells. Further, if we connect both the bi-inline PACD model and uni-inline PACD model to the same material handling model of Fig.5, we can obtain a PACD model of a heterogeneous job shop.

\section{Implementation}

This section presents the results of implementing a dedicated simulator executing the PACD model (See Fig.5) of a homogeneous job shop having bi-inline cells. The development of the dedicated simulator has been explained in detail in the literature [11]. The dedicated simulator implemented in C\# language is posted at http://www.vms-technology.com/ (Publication menu). The simulator is set to start with an empty system (i.e., all initial markings in the entity queues are set to zero) for the sake of simplicity, which makes it an offline simulator. However, if we set the initial markings to real-time WIP values, it becomes an online simulator.

Tables 1 and 2 show the route data and machine master data, respectively, for a homogeneous job shop having bi-inline cells (See Fig.1). In the experiment, 140 cassettes are released at time 0: 10 cassettes of type-2 jobs (glasses), 20 cassettes of type1 jobs, 70 cassettes of type- 2 jobs, and 40 cassettes of type- 1 jobs. 
Table 1. Route data for experiment

\begin{tabular}{|c|c|c|c|c|c|c|c|c|c|c|c|c|c|c|c|c|c|c|c|c|}
\hline & \begin{tabular}{|l} 
step-1 \\
$(p=1)$
\end{tabular} & \begin{tabular}{|c|} 
step-2 \\
$(p=2)$
\end{tabular} & \begin{tabular}{|} 
Step-3 \\
$(p=3)$
\end{tabular} & $\begin{array}{l}\text { Step-4 } \\
(p=4)\end{array}$ & $\begin{array}{l}\text { step-5 } \\
(p=5)\end{array}$ & \begin{tabular}{|c} 
Step-6 \\
$(p=6)$
\end{tabular} & $\begin{array}{c}\text { Step-7 } \\
(p=7)\end{array}$ & $\left|\begin{array}{c}\text { thep-8 } \\
(p=8)\end{array}\right|$ & $\mid \begin{array}{l}\mid \begin{array}{l}\text { tep-9 } \\
(p=9)\end{array} \\
\end{array}$ & $\mid \begin{array}{c}\left|\begin{array}{c}\text { tep-10 } \\
(p=10)\end{array}\right| \\
\mid\end{array}$ & $\begin{array}{l}\text { Step-11 } \\
(p=11)\end{array}$ & $\begin{array}{l}-5 \text { tep-12 } \\
(p=12)\end{array}$ & $\left.\mid \begin{array}{c}5 \text { tep-13 } \\
(p=13)\end{array}\right)$ & $\begin{array}{l}\text { Step-14 } \\
(p=14)\end{array}$ & $\begin{array}{l}4 \text { Step-15 } \\
(p=15)\end{array}$ & $\begin{array}{l}{\left[\begin{array}{l}\text { Step-16 } \\
(p=16)\end{array}\right.} \\
0\end{array}$ & 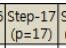 & $\begin{array}{l}\mid \begin{array}{l}5 \\
(p=18)-18\end{array} \\
\end{array}$ & 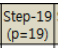 & \\
\hline $\begin{array}{c}\text { Type-1 } \\
(j=1)\end{array}$ & $\{1,2\}$ & $(3,4)$ & $\{5,6\}$ & $(7,8)$ & $\{1,2\}$ & $(3,4)$ & $\{5,6]$ & $\{7,8\}$ & $\{1,2\}$ & $\{3,4\}$ & $\{5,6\}$ & $\{7,8\}$ & $\{1,2\}$ & $\{3,4\}$ & $\{5,6\}$ & $\{7,8\}$ & - & - & - & - \\
\hline $\begin{array}{c}\text { Type-2 } \\
(j=2)\end{array}$ & $\{1,2\}$ & $\{3,4\}$ & $(5,6)$ & $(7,8)$ & $\{1,2\}$ & $\{3,4\}$ & $\{5,6\}$ & $(7,8)$ & $\{1,2\}$ & $\{3,4\}$ & $\{5,6\}$ & $\{7,8\}$ & \begin{tabular}{|l}
$\mid\{1,2\}$ \\
\end{tabular} & $\{3,4\}$ & $\{5,6]$ & $\{7,8\}$ & $\{1,2\}$ & $\{3,4\}$ & $\{5,6\}$ & $\{7,8\}$ \\
\hline
\end{tabular}

Table 2. Machine master data for experiment

\begin{tabular}{|c|c|c|c|c|c|c|c|c|c|c|}
\hline \multirow[b]{2}{*}{$\begin{array}{l}\text { Machine } \\
\text { ID (b) }\end{array}$} & \multirow[b]{2}{*}{ Description } & \multicolumn{6}{|c|}{ Time Data } & \multicolumn{3}{|c|}{ Capacity Data } \\
\hline & & $\left|\begin{array}{c}\text { Enter } \\
\text { time (tE[b]) }\end{array}\right|$ & $\begin{array}{c}\text { Load-to-inport } \\
\text { time (tLPI[b]) }\end{array}$ & $\begin{array}{l}\text { Total track-in/out } \\
\text { time (tTIO[b]) }\end{array}$ & $\left|\begin{array}{c}\text { Flow time } \\
(\pi[b])\end{array}\right|$ & $\begin{array}{c}\text { Setup time } \\
(\mathrm{t} S[\mathrm{~b}])\end{array}$ & $\begin{array}{c}\text { Supply time } \\
\text { (tSEC[b]) }\end{array}$ & $\begin{array}{l}\text { In-port } \\
\text { (pi[b]) }\end{array}$ & $\begin{array}{c}\text { Out-port } \\
\text { (po[b]) }\end{array}$ & $\begin{array}{l}\text { Inline } \\
(n[b])\end{array}$ \\
\hline 1 & \begin{tabular}{|l|} 
Cleaning-01 \\
\end{tabular} & 0 & 0 & 90 & 180 & 0 & 10 & 1 & 2 & 2 \\
\hline 2 & \begin{tabular}{|l|} 
Cleaning- 02 \\
\end{tabular} & 0 & 0 & 90 & 180 & 0 & 10 & 1 & 2 & 2 \\
\hline 3 & Deposition-01 & 0 & 0 & 99 & 280 & 0 & 10 & 1 & 2 & 2 \\
\hline 4 & Deposition-01 & 0 & 0 & 99 & 280 & 0 & 10 & 1 & 2 & 2 \\
\hline 5 & Photo-01 & 0 & 0 & 144 & 800 & 120 & 10 & 2 & 2 & 5 \\
\hline 6 & Photo-02 & 0 & 0 & 144 & 800 & 120 & 10 & 2 & 2 & 5 \\
\hline 7 & Etching-01 & 0 & 0 & 99 & 360 & 0 & 10 & 1 & 2 & 3 \\
\hline 8 & Etching-02 & 0 & 0 & 99 & 360 & 0 & 10 & 1 & 2 & 3 \\
\hline
\end{tabular}

The simulation results are presented in Fig. 7. Fig. 7(a) shows the utilization rate of each bi-inline cell. Notice that the pairs of identical machines have the same utilization rates; this is expected because a machine selection rule of 'smallest-queue-length' was used. Trends of increasing TAT (turn-around-time) also can be observed, indicating that the Fab is becoming congested as more cassettes are released. The disconnections (drops and jumps) in TAT curve Fig. 7 (b) are the results of job type changes.

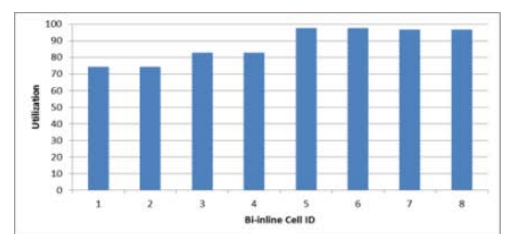

(a)

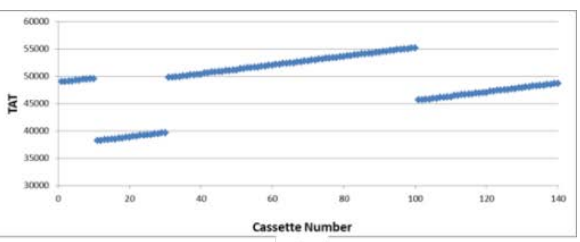

(b)

Fig. 7. (a) Utilization for bi-inline cells, (b) Turn-around time for cassette distribution

\section{$5 \quad$ Summary and Conclusions}

This paper presents a systematic procedure for building and initializing an ACD model of a homogeneous job shop with inline cells. First, the ACD models of a bi-inline cell and a uni-inline cell are presented. Second, the ACD models of the bi-inline cell and a simplified material handling system are combined to form a PACD model of a homogeneous job shop having inline cells. Finally, the initial marking values for initializing the model are obtained from the current state data of the Fab. The resulting PACD model was verified with a dedicated simulator using sample input data. This model can be implemented within a production simulator, which can be used in an online simulation for real-time operation management. In order to develop a more realistic model, further study is required to accommodate a heterogeneous job shop consisting of different types of inline cells with detailed AMHS. 


\section{Acknowledgement}

The research was supported by the NRF of Korea grant funded by the Korean Government (NRF-2013R1A1A2062607) to which the authors are grateful.

\section{References}

1. Jang, Y.J., Choi, G.H.: Introduction to Automated Material Handling Systems in LCD Panel Production Lines. In: 2006 International Conference on Automation Science and Engineering, pp. 223-229. IEEE (2006)

2. Lee, J.H.: A Study on Equipment Modeling Method for Simulation Based Semiconductor Fab Scheduling. M.S. Thesis, Department of Industrial and Systems Engineering, KAIST (2007)

3. Park, B.C., Park, E.S., Choi, B.K., Kim, B.H., Lee, J.H.: Simulation based planning and scheduling system for TFT-LCD Fab. In: 2008 Winter Simulation Conference, pp. 12621267. IEEE (2008)

4. Heilala, J., Montonen, J., Järvinen, P., Kivikunnas, S., Maantil, M., Sillanopää, J., Jokinen, T.: Developing Simulation-based Decision Support Systems for Customer-driven Manufacturing Operation Planning. In: 2010 Winter Simulation Conference, pp. 3363-3375. IEEE (2010)

5. Frantzén, M., Ng, A.H.C., Moore, P.: A Simulation-based Scheduling System for Realtime Optimization and Decision Making Support. Robotics and Computer-Integrated Manufacturing 27, 696-705 (2011)

6. Hanisch, A., Tolujew, J., Schulze, T.: Initialization of Online Simulation Models. In: 2005 Winter Simulation Conference, pp. 1795-1803. IEEE (2005)

7. Pool, M., Bachrach, R.: Productivity modeling of semiconductor manufacturing equipment. In: 2000 Winter Simulation Conference, pp. 1423-1427, IEEE (2000)

8. Potti, K., Gupta, A.: ASAP applications of simulation modeling in a wafer Fab. In: 2002 Winter Simulation Conference, pp. 1846-1848, IEEE (2002)

9. Gan, B.P., Liow, L.F., Gupta, A.K., Lendermann, P., Turner, S.J., Wang, X.: Analysis of a borderless Fab using interoperating autosched AP models. International Journal of Production Research 45 (3), 675-697 (2007)

10. Olaitana, O., Geraghty, J., Young, P., Dagkakis, G., Heavey, C., Bayer, M., Perrin, J., Robin, S.: Implementing ManPy, a Semantic-free Open-source Discrete Event Simulation Package, in a Job Shop. In: 8th International Conference on Digital Enterprise Technology, pp. 253-260, Procedia CIRP 25 (2014)

11. Choi, B.K., Kang, D.: Modeling and Simulation of Discrete-Event Systems. John Wiley \& Sons (2013)

12. Song, E., Choi, B.K., Park, B.: Event Graph Modeling of a Homogeneous Job Shop with Bi-inline Cells. Simulation Modelling Practice and Theory 20 (1), 1-11 (2012)

13. Kang, D., Kim, H., Choi, B.K., Kim, B.H.: Event Graph Modeling of a Heterogeneous Job Shop with Inline Cells. In: 2014 Winter Simulation Conference, pp. 2156-2167 (2014)

14. Choi, B.K., Kang, D., Lee, T., Jamjoom, A.A., Abulkhair, M.F.: Parameterized ACD and its application. ACM Trans. Model. Comput. Simul., 23 (4), Article No. 24 (2013) 